PATENT CLEARANCE IS NOT REQUIRED PRIOR TO THE PUBLICATION OF THIS DOCUMENT
$\mathrm{DOE} / \mathrm{PC} / 89777--\mathrm{T} 7$

DE92 009078

TECHNICAL PROGRESS REPORT

DOE Grant \#DE-FG22-89PC89777

Reporting Period: 9/1/91 - 11/30/91

Work during the ninth period of the grant period focused on continuous addition of oxygen to hydrogen during gasification, on active surface area measurements, and on overall analysis of the data collected on the project.

\title{
RESULTS
}

Continuous addition of oxygen: Earlier results on intermittent oxidative treatment between exposure to hydrogen showed as much as a three-fold increase in subsequent hydrogasification rate. Carbon porosity and total surface area were not substantially changed during these treatments, which led us to conclude that oxidation enhances rate by fixing oxygen groups on the carbon surface. These groups desorb to leave reactive sites at which hydrogasification occurs.

We purchased a mixture of $100 \mathrm{ppm} \mathrm{O}_{2}$ in hydrogen in order to study the possibility of oxidizing the carbon sample in-situ during hydrogasification. Based on the normal flow rate of $300 \mathrm{~cm}^{3}$ (STP)/min hydrogen and a nominal sample size of 0.5 grams, this could result in a maximum conversion of char to $C O$ of about $0.48 / \mathrm{hr}$. At usual hydrogasification conditions, this represents about 58 of the total char conversion rate of $6-108 / \mathrm{hr}$.

Several blank runs were conducted to test whether molecular oxygen reacted with molecular hydrogen in the gasification system. First, the test gas mixture was passed through the reactor at room temperature. It was found that, within the error involved with relatively low oxygen concentrations, nearly all oxygen passed through the system unreacted. The same test was performed with the reactor heated to $725^{\circ} \mathrm{C}$, making sure all metal which could come in contact with the mixture was removed from the reactor. Again, most of the oxygen passed through the system unreacted. A third test was then carried out, in which the metal springs holding the sample mount together and the reactor thermocouples were replaced. The resultant oxygen analysis showed that only about half as much oxygen was recovered when the metal was present, indicating that substantial water formation was taking place on the metal surface.

Following these blank runs, gasification of Saran char in the $100 \mathrm{ppm}$ oxygen in hydrogen mixture was carried out at usual gasification conditions of $725^{\circ} \mathrm{C}$ and $3.3 \mathrm{MPa}$ pressure. It was decided to conduct the gasification in the presence of the metal components in the reactor in spite of the apparent reaction taking place on the metal, as it was thought that enough unreacted oxygen would be present to oxidize the char surface. During this gasification, no oxygen peaks were observed in the effluent gas, and no measurable peaks of $\mathrm{CO}$ or $\mathrm{CO}_{2}$. Further, the observed methane formation rate was the same for this gas mixture as in pure hydrogen feed.

These results lead to several possible explanations. First, it is almost certain that any molecular oxygen which came in contact with the carbon sample interacted with the carbon. In the highly reducing environment, however, this oxygen probably was converted to water via reaction with hydrogen. We cannot detect water vapor with our chromatographic column, and this is probably where the oxygen went to. The absence of measurable $\mathrm{CO}$ and $\mathrm{CO}_{2}$ peaks, which would not 
have been very large anyway, suggests that formation of these products is not the primary route of oxygen consumption.

We believe that the concentration of oxygen used is too small to effectively change the carbon surface to a more oxidized state. It would be appropriate at a future time to investigate higher oxygen or other oxidizing gas concentrations in hydrogen. Other investigators have reported that continuous addition of oxygen to hydrogen can enhance methane formation rate.

ASA Measurements: Initial measurements of active surface area (ASA) of coal char samples using pulse oxygen chemisorption did not seem to provide an appropriate basis for gasification rate. In recent tests, we have found that the ash present in the coal char has a major effect on the ASA measurement. We subjected a sample of coal ash, obtained by burning coal in air at $500^{\circ} \mathrm{C}$, to the conditions of hydrogasification. Upon removing the sample and placing it in the ASA measuremnts apparatus without exposing it to air, we found an ASA for the ash of about $70 \mathrm{~m}^{2} / \mathrm{g}$. This value exceed the TSA for the ash, indicating that at hydrogasification conditions the coal ash is in a significantly reduced state. Upon exposure to oxygen in ASA measurements, the ash reoxidized, resulting in a large uptake of oxygen and the false high ASA result. This is an important result, as it indicates to us that ASA measurement using molecular oxygen is not possible for ash-containing samples in hydrogasification.

We thus confined our ASA measurements to Saran char, which contains essentially no ash. The measurements were conducted by first outgassing a char sample to $725^{\circ} \mathrm{C}$ and then exposing the sample to successive pulses of oxygen at $295^{\circ} \mathrm{C}$. The temperature of $725^{\circ} \mathrm{C}$ was chosen for outgassing to match the reaction temperature; any oxygen groups stable above this temperature would not expect to desorb during gasification, and thus would not participate in creating active surface area for gasification.

Results of ASA measurements over the course of an intermittent oxidation are shown in Table I (attached), where ASA is reported following hydrogasification or exposure to molecular oxygen at $375^{\circ} \mathrm{C}$. The conversions for both the gasification and oxidation steps are reported (negative conversion indicates weight gain). The initial Saran char ASA is about $5 \mathrm{~m}^{2} / \mathrm{g}$. It is seen that ASA increases over the course of hydrogasification and decreases following oxidation. This is directly opposite to the trend observed for hydrogasification rate (Figure 1). The results of both ASA and rate measurements are reproducible and thus must be considered valid. It is apparent that ASA measurement via our method is not giving a surface area representative of that at which hydrogasification occurs .

We believe that oxygen and hydrogen are interacting on the char surface. When char is gasified in hydrogen, the surface contains adsorbed hydrogen. Upon exposure to oxygen in ASA measurement following hydrogasification, the adsorbed hydrogen reacts with oxygen to form water vapor. The loss of hydrogen from the surface then leaves an unsaturated carbon at which a second oxygen atom or molecule can adsorb. This results in a net higher apparent ASA. Following partial oxidation, however, many surface sltes are occupied by oxygen which does not desorb during the $725^{\circ} \mathrm{C}$ outgassing before ASA measurement. Thus, a lower apparent surface area is observed. The fact that hydrogen reduces the carbon surface and apparently can reduce the oxygen surface groups present on the surface indicates that oxygen chemisorption is likely not an appropriate means of measuring ASA for hydrogasification. It would be appropriate to investigate outgassing the char samples to much higher temperatures $\left(1100^{\circ} \mathrm{C}\right)$ before ASA measurements in order to determine if removal of all oxygen groups gives a better representation of ASA for hydrogasification. 


\section{ANALYSIS OF RESULTS}

As we continue analyses of results of this study under the support of DOE, we have come to several conclusions regarding hydrogasification and the behavior of the char samples studied. First, we observe that hydrogasification rate of uncatalyzed chars declines very strongly with char conversion. Figure 2 gives hydrogasification rate versus conversion for two runs; rates at the low temperature $\left(600^{\circ} \mathrm{C}\right)$ are normalized to those at $725^{\circ} \mathrm{C}$ using the activation energy calculated earlier in our study $(67 \mathrm{kcal} / \mathrm{gmol})$. We belleve that this strong decline results from a loss of active sites as carbon is converted. Active sites are lost in hydrogasification because of consumption of reactive carbon and loss of oxygen surface groups. Unlike in oxidizing environments, the char surface becomes progressively more reduced as gasification in hydrogen takes place. Because oxygen surface groups are known to play such a major role in char surface activity, we belleve this loss of surface oxygen groups is primarily responsible for the char deactivation. Based on our studies of hydrogen treatements at conditions apart from gasification, we do not believe that strong, irreversible hydrogen adsorption on the char surface is responsible for decay in char reactivity.

In $\mathrm{K}_{2} \mathrm{CO}_{3}$-catalyzed hydrogasification, the presence of ash has a tremendous deactivating effect on char reactivity (Figure 3 ). In addition to the formation of compounds with ash components, we believe that the catalyst is further deactivated by the reduced ash, which serves to more easily withdraw oxygen from the char surface.

\section{CONTINUING WORK}

Work for the last three-month period of the grant will focus on continuing analysis and workup of the data collected throughout the course of the project.

\section{DISCLAIMER}

This report was prepared as an account of work sponsored by an agency of the United States Neither the United States Government nor any agency thereof, nor any of their exployees, makes any werranty, express or implied, or assumes any legal liability or responsi-

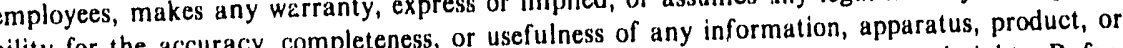
process disclosed, or represents that its use would not infringe privately owned rights. Referprocis drade name, trademark, manufacturer, or otherwise does not necessarily constitute or imply its endorsement, recommendation, or favoring by the United States Government or any agency thereof. The views mendation, or favoring by the United States do not necessarily state or reflect those of the United States Government or any agency thereof. 
TABLE 1. ACTIVE SURFACE AREA OF INTERMITTENTLY OXIDIZED SARAN - TWO DIFFERENT RUNS

$\%$ conversion

Run A Run B

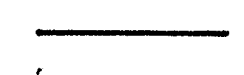

Gas. \#1:

oxi. \#1:

Gas. \#2:

$-1.24-1.75$

Gas. \#3 :
$A S A\left(\mathfrak{m}^{2} / g C\right)$

Run A Run B

\begin{abstract}
oxi. \#2:
\end{abstract}

$$
19.9
$$

21.0

$\mathrm{NA}$

14.5

14.7

$0.32-2.5 I$

4.9

$4 \cdot 3$

6.1

4.0

$>5 . I$

3.4

24.7

NA

6.6 


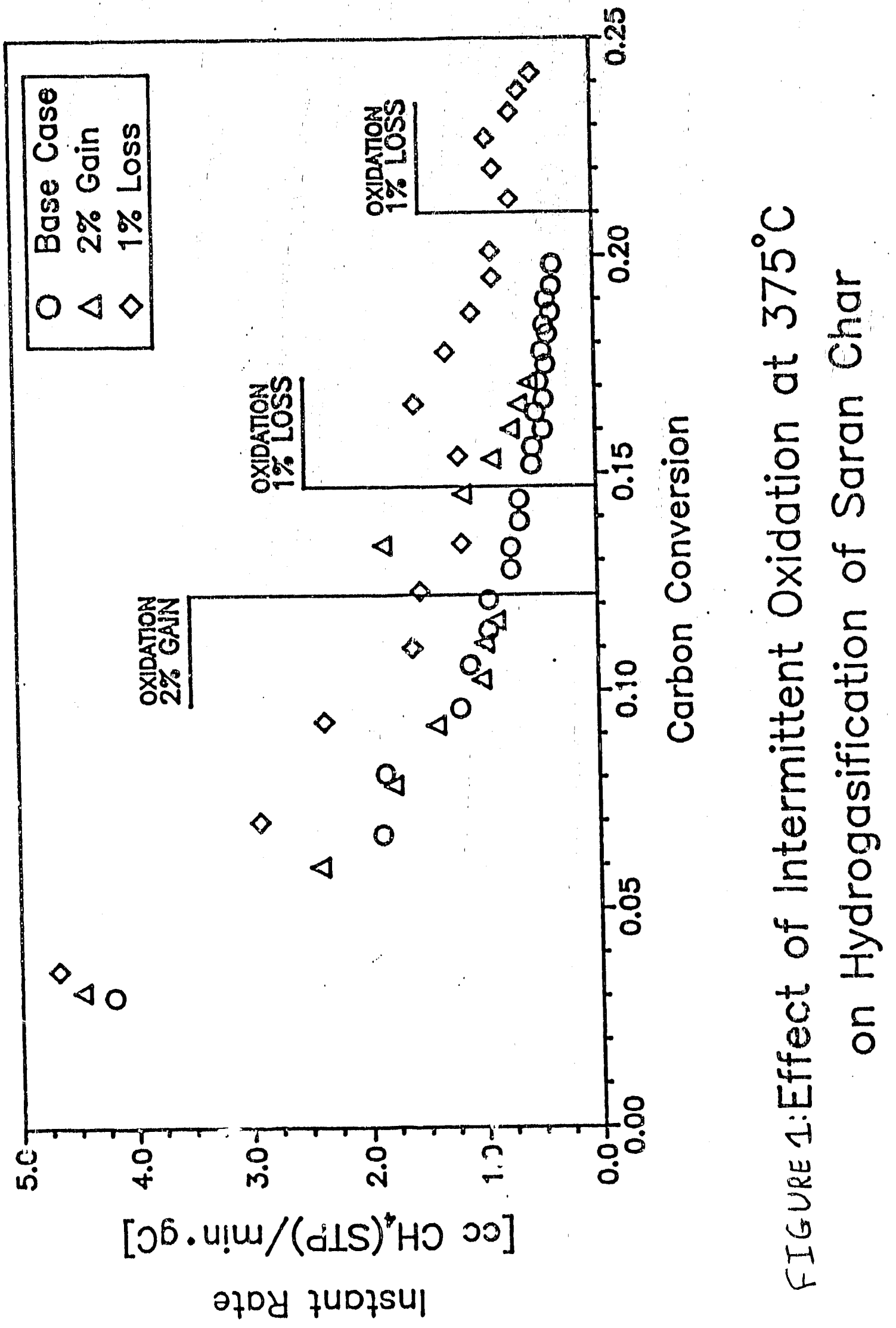




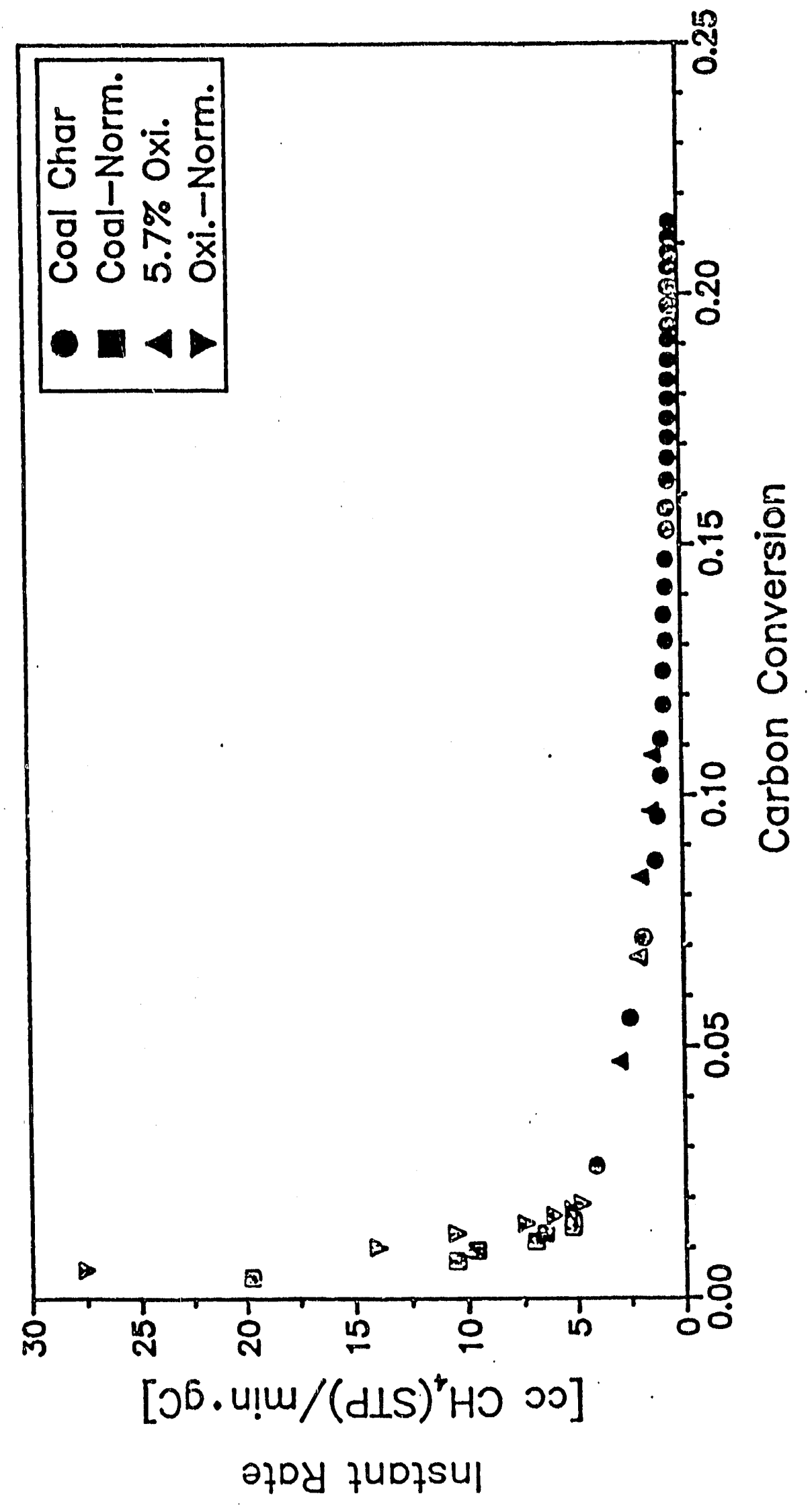

$\frac{1}{4}$

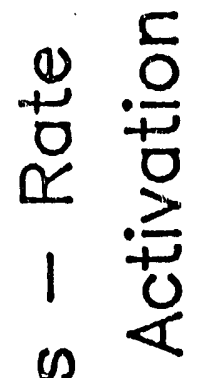

$\frac{1}{\frac{1}{0}} \cdot \frac{0}{2}$

00

o 10

O N

$\circlearrowleft N$

ᄂᄂ

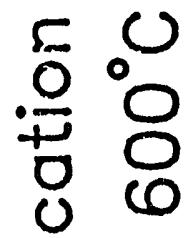

遂

0 는

인

우

I $\frac{N}{0}$

. E

$\stackrel{\sim}{\leftrightarrows} \frac{1}{\zeta}$

5 


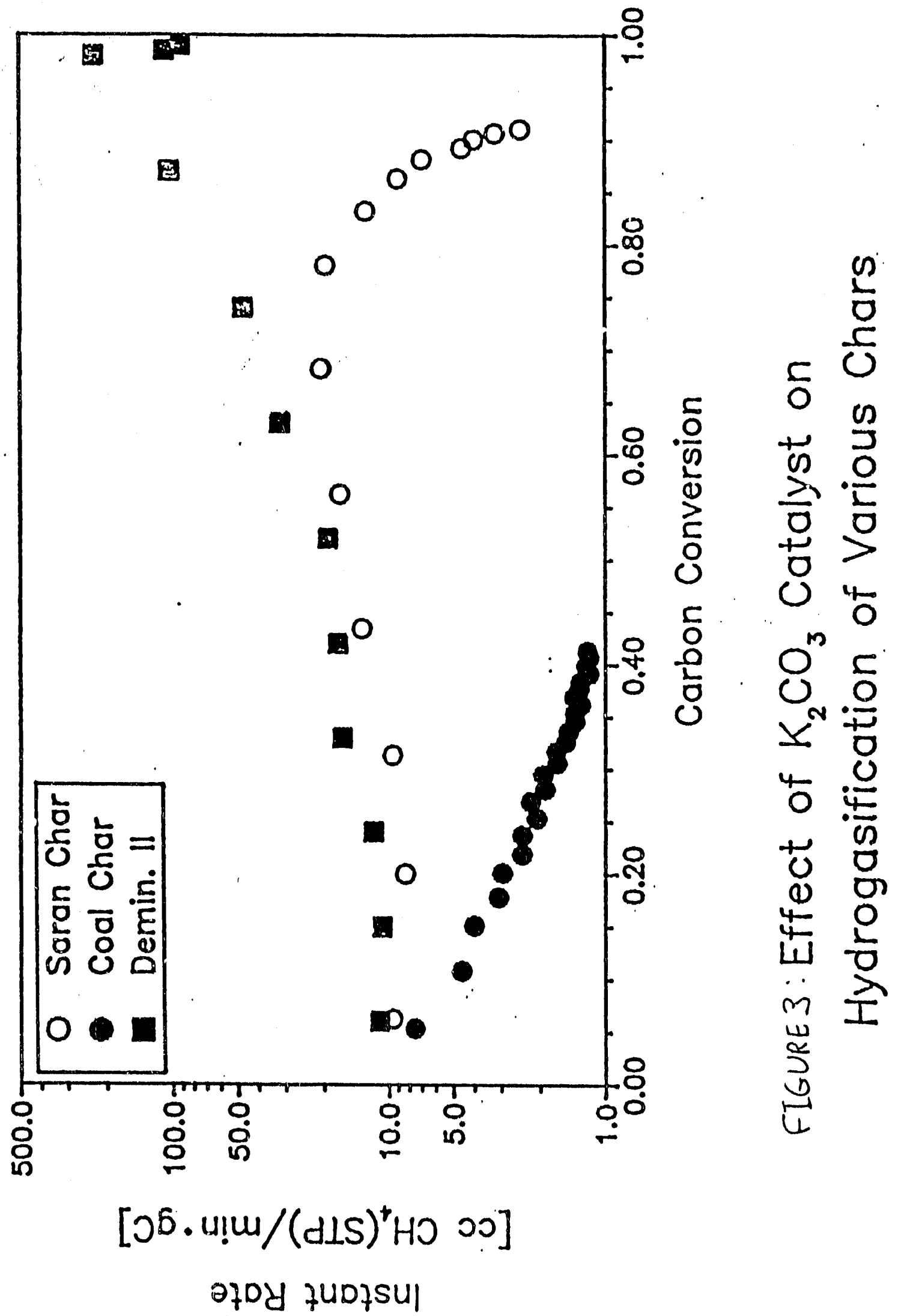



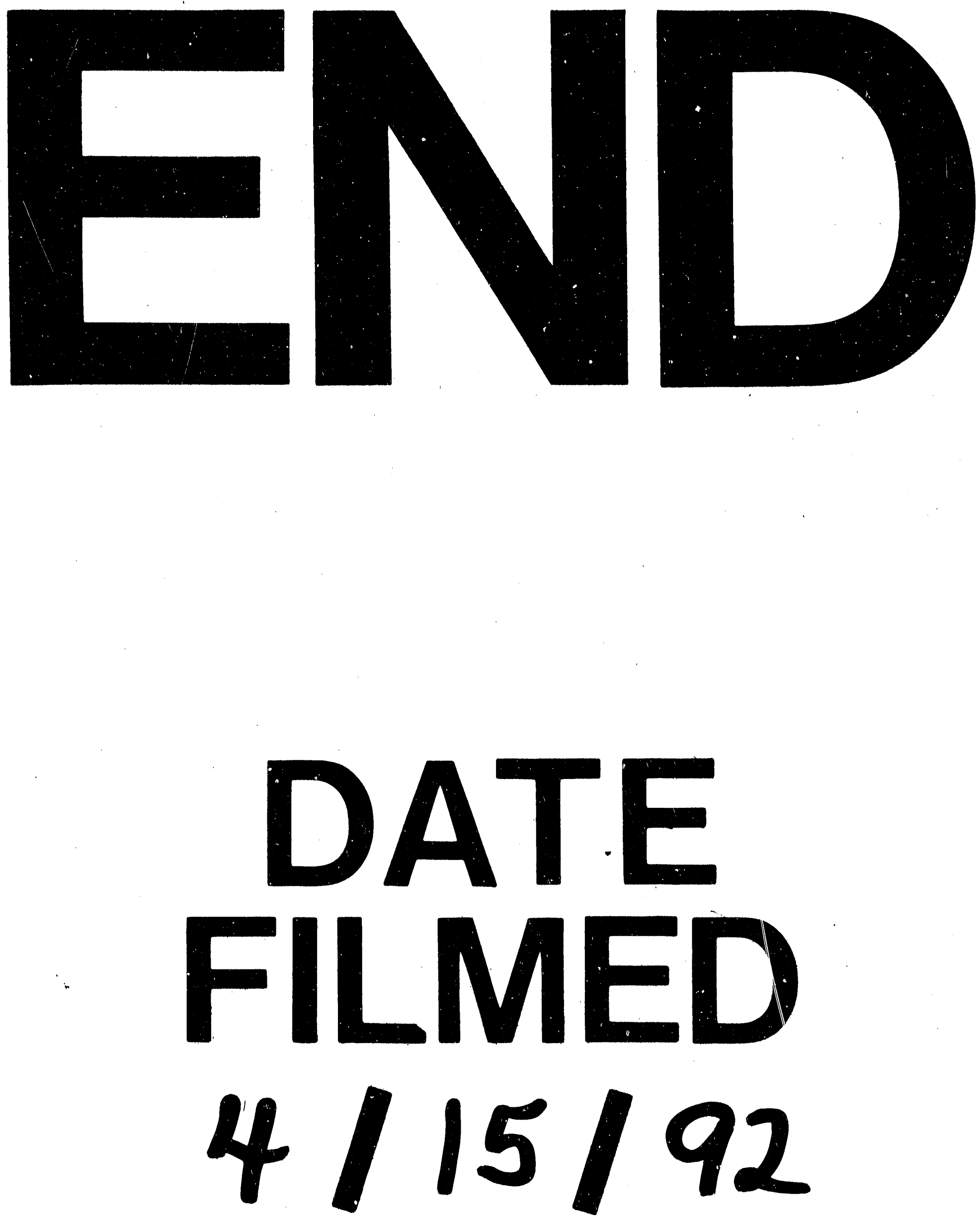
